\title{
Using forage litter to improve soil degradation of pure Betula platyphylla forest in the Loess Plateau, China
}

\author{
Luc Nhu Trung ${ }^{1,2}$, Zengwen Liu ${ }^{3,4 *}$, Xiaoxi Zhang ${ }^{5}$, \\ Yuanhao Bing ${ }^{6}$ and Bochao $\mathrm{Zhu}^{7}$
}

Trung, L.N., Liu, Z., Zhang, X., Bing, Y., Zhu, B. 2013. Using forage litter to improve soil degradation of pure Betula platyphylla forest in the Loess Plateau, China. Forestry Studies | Metsanduslikud Uurimused 59, 5-12. ISSN 1406-9954. Journal homepage: http://mi.emu.ee/forestry.studies

\begin{abstract}
The long-term growth of pure forest is an important issue that affects stability and sustainable development of ecosystem, while using forage litter as fertilizer or directly establishing tree-grass complex vegetation may be the most effective prevention way. This study took the artificial pure forests of Betula platyphylla, which were widely distributed in the Loess Plateau of China, as the object and conducted a 120-day decomposition incubation experiment of forest humus soil mixed with seven common leguminous forage litters to study the effects of forage litters in controlling the degradation of soil biological and chemical properties of pure forests. The results showed that: by adding forage litter to the soil of pure B. platyphylla forest, litters of Lespedeza bicolor and Onobrychis viciaefolia improved the soil quality obviously, followed by Astragalus adsurgens and Melilotus officinalis, while Medicago sativa lead to obvious deterioration, followed by Vicia villosa and Coronilla varia.
\end{abstract}

Key words: forage litter, Betula platyphylla, pure forest, soil degradation.

Authors' addresses: 'Institute of Soil and Water Conservation, Northwest A\&F University, Yangling 712100, Shaanxi, China, e-mail: trungfrc@gmail.com; ${ }^{2}$ Department of Agriculture and Rural Development of Lao Cai, Lao Cai City 330100 Vietnam, e-mail: lntrung-snnptnt@laocai.gov.vn; ${ }^{3}$ College of Natural Resources and Environment, Northwest A\&F University, Yangling 712100, Shaanxi, China; ${ }^{4}$ Key Laboratory of Plant Nutrition and the Agri-environment in Northwest China Ministry of Agriculture, Yangling 712100, Shaanxi, China; ${ }^{5}$ Institute of Soil and Water Conservation, Northwest A\&F University, Yangling 712100, Shaanxi, China, e-mail: zhangxiaoxi712100@gmail.com; ${ }^{6}$ College of Forestry, Northwest A\&F University, Yangling 712100, Shaanxi, China, e-mail: yy198766@163.com; ${ }^{7}$ College of Natural Resources and Environment, Northwest A\&F University, Yangling 712100, Shaanxi, China; *e-mail: zengwenliu2003@aliyun.com

Introduction

Artificial pure forest made of Betula platyphylla Sukaczev, one of the main afforestation of broad-leaved tree species in the Loess Plateau, is important vegetation type for comprehensive treatment of the Loess Plateau of China. However, it has been reported in large number of studies that after long-term growth or continuous planting for several generations, pure forest often results in soil deterioration (Joshi et al., 1997; Zhang \& Cai, 2004). The reasons include pure forest's extreme selection of absorbing and returning of soil nutrient, and the particular impact of the single tree species litter on soil biochemical properties, which cause the soil properties deviating from its original equilibrium to a negative (destroy) development. Previous studies indicated that, in the central hilly area of the Loess Plateau (took Huangling of Shaanxi province as an example), the pure forest of B. platyphylla had resulted in 
Table 1. Introduction of pure forests.

\begin{tabular}{lcccccccc}
\hline Pure forests & $\begin{array}{c}\text { Physiognomy } \\
\text { positions }\end{array}$ & $\begin{array}{c}\text { Altitude } \\
(\mathrm{m})\end{array}$ & $\begin{array}{c}\text { Aspect } \\
\text { B. platyphylla }\end{array}$ & $\begin{array}{c}\text { Slope } \\
\left({ }^{\circ}\right)\end{array}$ & $\begin{array}{c}\text { Average } \\
\text { age }\end{array}$ & $\begin{array}{c}\text { Density } \\
\left(/ \mathrm{hm}^{-2}\right)\end{array}$ & $\begin{array}{c}\text { BWD } \\
(\mathrm{cm})\end{array}$ & $\begin{array}{c}\text { Average } \\
\text { height } \\
(\mathrm{m})\end{array}$ \\
\hline
\end{tabular}

a huge loss of soil available $\mathrm{P}$ and $\mathrm{K}$, and decrease of activities of enzymes such as sucrase and phosphatase, while the activity of protease was increased to some extent (Liu et al., 2007; Liu et al., 2009).

In terms of the soil degradation, establishing tree-grass complex vegetation is the most effective solution to prevent it, not only because of the rapid growth of grass and the wide range source of litter (Zhang et al., 2013), but also a large amount of forage (especially leguminous forage) can improve soil properties in terms of total $\mathrm{N}$, available $\mathrm{P}$ and $\mathrm{K}$ contents, as well as the other soil biochemical properties (Li, 2008; Pan et al., 2011). According to the above assumption, in this study, humus soil in the pure forests of B. platyphylla were gathered and a 120-day decomposition incubation experiment of forest soils mixed with seven common leguminous forage litters were conducted to study the effects of forage litters on soil, in order to bring some scientific guidance for the prevention of soil degradation and the improvement of local pure forests.

\section{Material and Methods}

\section{Study sites}

Soil from B. platyphylla pure forest plantations was collected from Huangling county of Shaanxi province, China (Table 1). This area is located in a typical hilly region of the Loess Plateau. This region is classified assemi-humid warm-temperate zone, with an average annual temperature of $9.4{ }^{\circ} \mathrm{C}$. The average annual rainfall is $630.9 \mathrm{~mm}$, the average frost-free period is approximately 150 days, and the relative humidity is approximately $64 \%$. The soil is a typical grey cinnamon soil, which is classified as Ultisols in the USDA Soil Taxonomy system.

\section{Collection of soil samples and forage litter}

For this study, soil collections were made from B. platyphylla pure forests that had reached the mature growth stage. In these forests, the tree growth density was greater than 0.9 , and the understory vegetation coverage was less than $15 \%$. Standard $20 \mathrm{~m} \times$ $20 \mathrm{~m}$ plots were established in typical locations in two forests, and the site factors and tree growth indexes were measured in these plots (Table 1). Five quadrats were established in the plots, each $1 \mathrm{~m} \times 1 \mathrm{~m}$. The humus layer of the soil was collected at a depth of $0-10 \mathrm{~cm}$ after removing the litter from the ground. The samples from each stand were then mixed to form a composite sample and transported to the laboratory, then passed through $5 \mathrm{~mm}$ mesh sieves to get rid of leaves, roots, and gravel. Simultaneously, litters from Astragalus adsurgens Pall., Lespedeza bicolor Turcz., Vicia villosa Roth, Coronilla varia L., Melilotus officinalis (L.) Pall., Medicago sativa L. and Onobrychis viciaefolia Scop. were collected in late autumn before withered, gently washed and oven-dried at $65{ }^{\circ} \mathrm{C}$ for $24 \mathrm{~h}$ to reach constant weight. The dry litter samples were then ground with a laboratory mill $(\varphi=$ $1 \mathrm{~mm})$.

\section{Decomposition incubation of soil mixtures with forage litter}

Prepared fresh soil samples and litter were mixed with a dry weight ratio of 100:2 (with the original forest soil with no litter as a control). A total of $2.5 \mathrm{~kg}$ mixed soil was placed in impermeable plastic pots with natural density. Each treatment had 
3 replications. Then, a measured amount of distilled water was added to each pot to adjust the soil moisture to $50 \%$ of saturated field capacity, pots were covered with plastic film with 4 holes for ventilation to reduce water loss, and incubated at room temperature $\left(20-25{ }^{\circ} \mathrm{C}\right)$. The pots were weighed every three days and distilled water was added with a sprayer to keep the weight of pots constant (so that the moisture was constant as well). Samples of mixed soil were incubated under these conditions for 120 days until inner litter decomposed and no residual visible to naked eye. After incubation, soil samples were placed on clean plates, and the remaining leaf litter was carefully removed. A part of soil was collected to measure the content of micro-organisms. The remaining soil samples were air-dried, and ground for the measurement of following biological and chemical properties.

\section{Measurements of soil properties}

Chemical properties: The chemical properties of the soil were measured according to methods suggested by $\mathrm{Lu}$ (1999). Soil $\mathrm{pH}$ was measured by glass electrode method (the ratio of soil to water was 1:2.5). Organic matter was determined with the potassium bichromate titrimetric method. Available nitrogen was measured with the micro-diffusion technique. Available phosphorus was measured by $\mathrm{NaHCO}_{3}$ extraction with the molybdenum blue colorimetric method. Available potassium was measured with the ammonium acetate extraction flame photometric method. Cation exchange capacity was measured with the sodium acetate-ammonium acetate flame photometric method.

Biological properties: The quantity of microorganisms was measured with the dilution plating method (Nanjing Institute of Soil Science..., 1985) (bacteria-beef extract peptone agar culture medium, fungi-potato dextrose agar culture medium, actinomyces-GAO 1st synthetic culture medium). Urease activity was mea- sured with the phenol sodium-sodium hypochlorite colorimetric method. Sucrase activity was measured with the $\mathrm{Na}_{2} \mathrm{~S}_{2} \mathrm{O}_{3}$ titration method. Catalase activity was measured with the $\mathrm{KMnO}_{4}$ titration method. Dehydrogenase activity was measured with the triphenyltetrazolium chloride colorimetric method. Alkaline phosphatase activity was measured with the disodium phenyl phosphate colorimetry method. Protease activity was measured with the ninhydrin colorimetric method. Polyphenol oxidase activity was measured with the iodometric titration method (Guan, 1986).

\section{Statistical analysis}

The data were analyzed with Microsoft Excel 2010 and SPSS 19.0 software. The significance of the differences between the effects of the forage litter types on the pure forest soil properties was evaluated with LSD test $(\alpha=0.05)$. For the addition of forage litter had complex effects on the 16 indexes of soil biochemistry, while even the same litter affected the soil properties at different extents and directions. Thus to assess the comprehensive effects of forage litters on soil properties, a comprehensive principal component analysis method was employed to analyze the rate of improvement of 15 biochemical properties $(\mathrm{pH}$ excluded) relative to the $\mathrm{CK}$ values of the control sample (soil without any litter mixed). This analysis was performed with SPSS 19.0, and the comprehensive principal component value $F_{i}$ was calculated (Figure 1). $F_{i}>0$ implies that the addition of forage litter can improve soil properties (by decreasing the rate of negative polarization or increasing the rate of positive polarization); in contrast, $F_{i}<0$ implies that the forage litter causes the soil properties to deteriorate.

\section{Results and Discussion}

According to the biochemical properties changed by adding different forage 
litter to the soil of pure B. platyphylla forest (Table 2), litters of $A$. adsurgens significantly increased the content of organic matter, available $\mathrm{N}$ and $\mathrm{K}$, the activity of sucrase and dehydrogenase, and activate the growth of fungi and actinomycetes, urease and catalase activity, and activate the growth of fungi and actinomycetes, but significantly reduced the activity of the urease, catalase and protease. Whereas L. bicolor significantly increased soil available $\mathrm{K}$ content, and activate the growth of fungi and actinomycetes, but significantly reduced the activity of the urease and catalase. $V$. villosa also significantly improved soil available $\mathrm{N}$ and $\mathrm{K}$ contents, the activity of sucrase in the soil, and promoted the growth of fungi and actinomycetes, but significantly reduced the activity of the urease, phosphatase and polyphenol oxidase. On the other hand, C. varia significantly increased the soil available $\mathrm{N}, \mathrm{K}$ contents, and the activity of sucrase, but meanwhile reduced the activity of the urease. An increased content of available $\mathrm{N}$ and $K$, enhandced activity of catalase and sucrase and active growth of fungi and actinomycetes were observed with $M$. officinalis treatment, but it significantly reduced the activity of the urease and protease. The effect of $M$. sativa was the same as $M$. officinalis except it significantly reduced the activity of polyphenol oxidase instead of protease. In contrary, O. viciaefolia significantly increased the content of available K, and the activity of the urease, sucrase and phosphatase, but significantly reduced the activity bacterial growth of catalase.

The comparison between the results of this study and the previous studies (the long-term growth of pure forest of B. platyphylla had resulted in a serious of degradation such as a huge loss of available N, P and $\mathrm{K}$ in soil and the decrease of sucrase, dehydrogenase, urease and phosphatase activity) showed that all forage litters reduced the loss of available $K$, in which the influence of $C$. varia was the most obvious. However, no forage litters improved the content of available P. All the forage could significantly mitigate the decrease of sucrase activity except L. bicolor, in which $M$. sativa showed the most obvious effect; $O$. viciaefolia could significantly mitigate the decrease of catalase activity, while $V$. villosa greatly exacerbated this trend.

Considering the impact of forage litter on the above degradation trends and the effect on other soil biochemical properties, according to the principal component analysis (Figure 1), after adding the forage litter to the soil of pure B. platyphylla forest, L. bicolor and O. viciaefolia showed obvious improvement effect, followed by $A$. adsurgens and $M$. officinalis; while $M$. sativa played an obvious deterioration role, followed by $V$. villosa and C. varia.

The previous studies showed that forage such as $A$. adsurgens, $M$. sativa, L. bicolor can improve the contents of total nitrogen and total phosphorus on the soil, among which, $M$. sativa associated with obvious improvement of total nitrogen, and $M$. sativa and A. adsurgens resulted in more obvious improvement of total phosphorus than L. bicolor (Zhang et al., 2008); O. viciaefolia and $M$. sativa improved organic matters and nitrogen contents of soil (Li, 2008); After C. varia was added to grey brown desert soil in Heihe valley, soil organic matters, available nitrogen, phosphorus and available potassium content were increased effectively (Wang \& Jin, 2006). This may be due to rich nitrogen of legume forages, and low carbon nitrogen ratio which enhanced the soil microbial activity (Hong et al., 2003). Therefore, there was an improvement in the soil organic matters as well as the available phosphorus and rapidly available potassium (Wang et al., 2011b). So, it is an effective means to rapidly improve the soil properties of pure forest and prevent the degradation of soil by means of quickly supplement of soil nutrient loss through the decomposition of other plant litter and the inducing the betterment of other biochemical properties. 


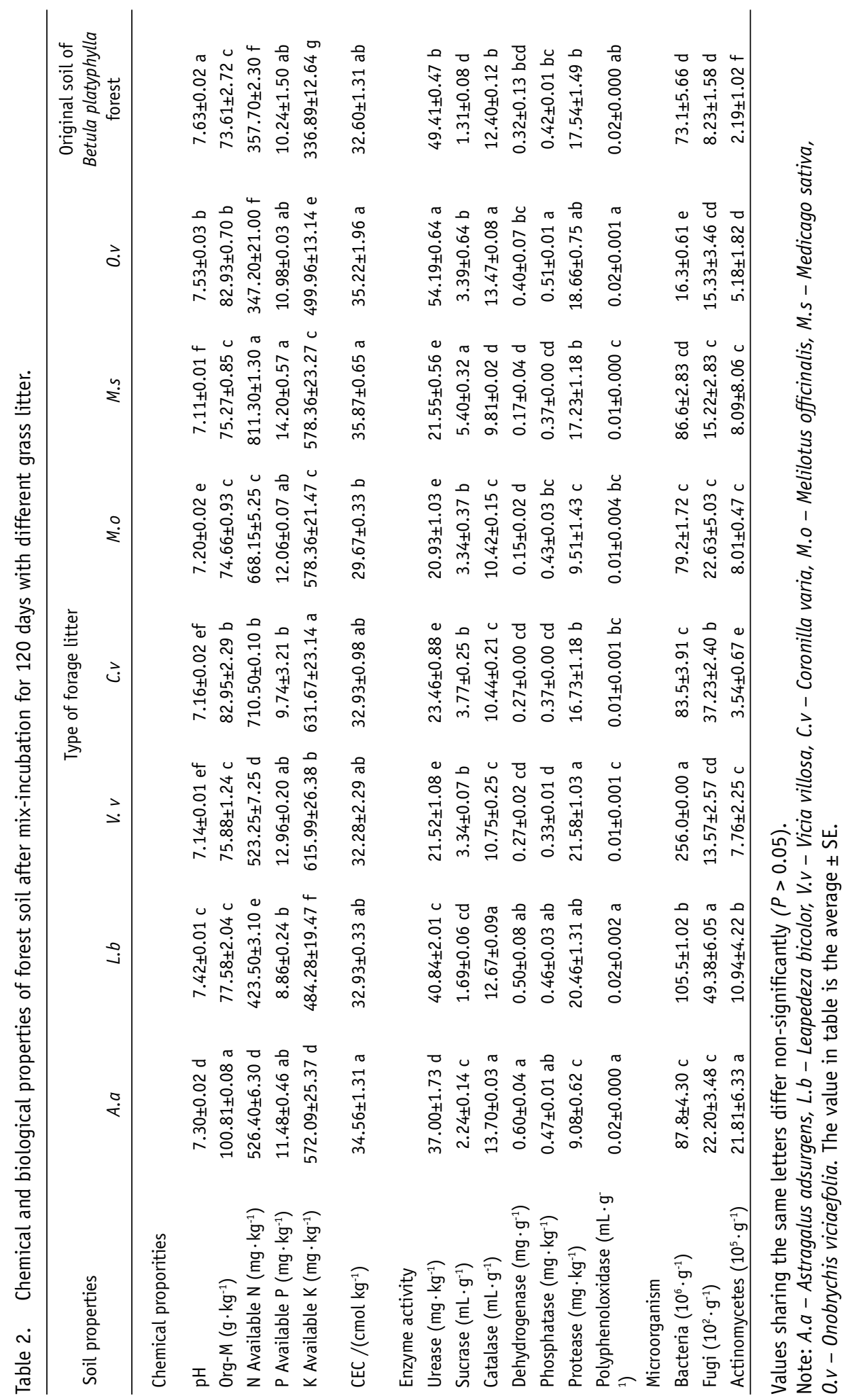




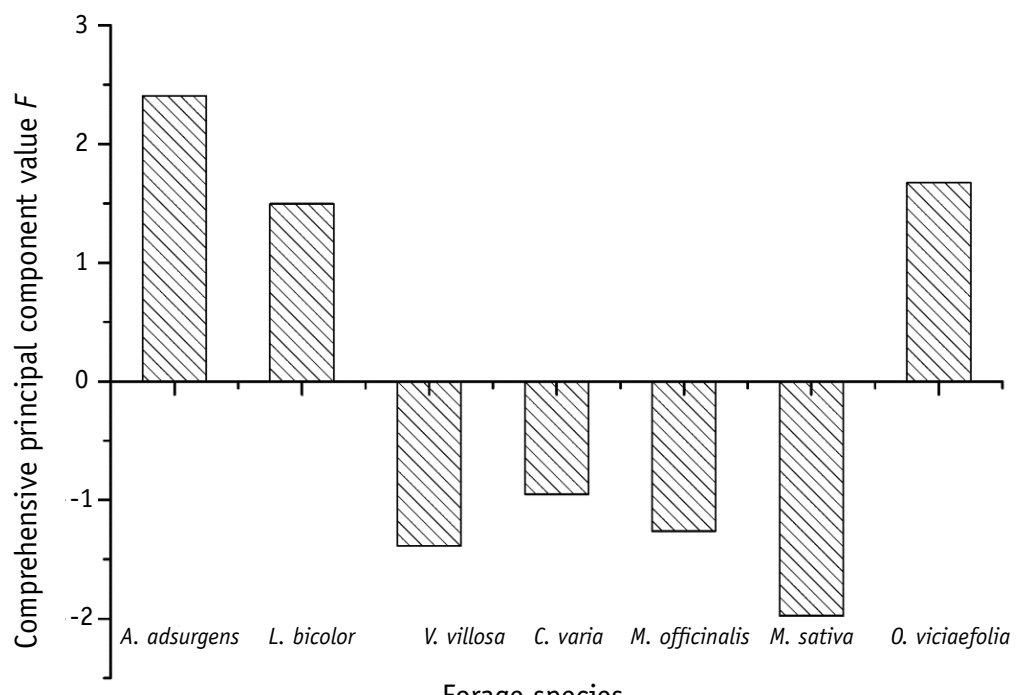

Forage species

Figure 1. Combined effects of forage litter on the soil of pure Betula platyphylla forest.

This test showed that, in Huangling region, all forage litter could not significantly increase the content of available $\mathrm{P}$ and mitigate its degradation trend, which is not similar to the findings of Li et al. (2011a). An important reason for the above results may be that the decomposition of the litter itself and soil organic matter utilized a mass of the available $\mathrm{P}$, because the decomposition of microbial requires appropriate $\mathrm{C} / \mathrm{P}(\mathrm{Li}$ et al., 2010; Zhao et al., 2011). The adding of all kinds of litter significantly alleviated the loss of available $\mathrm{K}$ or enhanced its increasing trend, which is similar to the findings of other scholars (Zhang et al., 2008). This is because that $\mathrm{K}$ is a non-structural element (Osono \& Takeda, 2004), which is more easily to release compared with $\mathrm{N}$ and P (Zhao et al., 2011). The release of a large number of water-soluble $\mathrm{K}$ will increase the content of soil available $\mathrm{K}$.

In terms of biological properties, adding variety of litters showed some improvement on enzyme activity, which is similar to the findings of Li (Liu et al., 2010; Li et al., 2011b; Wang et al., 2012). This might be caused due to enzymes released from lit- ters itself, or the products of decomposition stimulate the activity of enzyme system. Some litters inhibited some activity, even intensifying its negative trend, which is similar to the findings of Sun et al. (2011). Because there are certain correlation between different properties of soil, after having been added in the soil, forage litter can make direct effect on some certain properties as well as make indirect effect on other properties (Li, 1993; Liu et al., 2004; Wang et al., 2011a). The above phenomenon may be due to that the enzyme was affected by the change of some nutrient elements (Sun et al., 2011). The changes in microbial activity was also subjected to multiple factors, such as the substrate quality of the litter (Qi et al., 2004), the content of special chemical substance, and the nutrient of the soil itself. After adding of forage litters the microbial species, the quantity and even the microbial flora (Kourtev et al., 2002) would change, which needs to be further investigated and explained. 


\section{Conclusions}

All the forage litters increased the content of available $K$, in which the effect of $C$. varia was the most obvious. However, they could hardly control the loss of available P. All forage could improve sucrase activity except L. bicolor, and O. viciaefolia could improve catalase activity significantly.

The comprehensive analysis of results showed that after adding the forage litter to the soil of pure B. platyphylla forest, $L$. bicolor and $O$. viciaefolia got obvious improvement effects, followed by $A$. adsurgens and $M$. officinalis, and these forage may be suitable to be planted with $B$. platyphylla for combating the degradation of soil properties. M. sativa played an obvious deterioration role, followed by $V$. villosa and C. varia, these forage shouled avoid to be planted with $B$. platyphylla.

\section{References}

Guan, S.Y. 1986. Soil enzyme and research technology. Beijing, China Agriculture Press, 62-142. (In Chinese).

Hong, C.L, Wei, Y.Z., Huang, J.F., Wang, R., Yang, X. 2003. Effects of total crop straw return on soil fertility and field ecological environment. - Journal of Zhejiang University (Agric. \& Life Sci.), 29(6), 627-633. (In Chinese).

Joshi, M., Bargali, K., Bargali, S.S. 1997. Changes in physico-chemical properties and metabolic activity of soil in poplar plantations replacing natural broad-leaved forests in Kumaun Himalaya. Journal of Arid Environments, 35(1), 161-169.

Kourtev, P.S, Ehrenfeld, J.G., Huang, W.Z. 2002. Enzyme activities during litter decomposition of two exotic and two native plant species in hardwood forests of New Jersey. - Soil Biology and Biochemistry, 34(9), 1207-1218.

Li, S. 1993. Effect of fertility and activity of soil enzymes on legume. - Acta Pratacultural Science, 10(5), 20-23. (In Chinese with English abstract).

Li, X.B., Ma, L., Chen, L., Xu, D.M., Xie, Y.Z. 2010. Research progress and the prospect of grassland litters decomposition. Ecology and Environmental Sciences, 19(9), 2260-2264.

Li, Z., Liu, G.S, Jing, H.X., Ye, X.F., Xie, C.S., Xiang, Y.G., Zhang, W,P., Yang, C., Wang, Y., Xi, X.Y. 2011a. Effects of green manure application combined with chemical fertilizers on microbial biomass $\mathrm{C}, \mathrm{N}$ and nitrogen supplying characteristics of tobacco-planting soils. - Acta Prataculturae Sinica, 20(6), 126-134. (In Chinese).

Li, Z., Liu, G.S., Jing, H.X., Xie, C.S, Xiang, Y.G, Yang, C., Zheng, W.R., Ye, X.F. 2011b. Effects of green manure application on the microbial biomass $\mathrm{C}$ and $\mathrm{N}$ contents and of the enzyme activity of tobacco-planting soil. - Acta Prataculturae Sinica, 20(3), 225-232. (In Chinese).

Li, Z.L. 2008. Study of Onobrychis viciaefolia and Medicago sativa on yield and soil fertility. - Acta Pratacultural Science, 25(7), 65-68. (In Chinese with English abstract).

Liu, G.S., Li, Z., Jing, H.X., Ye, X.F., Shi, H.Z., Wang, Y., Yang, C., Chang, D. 2010. Effects of consecutive turnover of green manures on soilm icrobial biomass and enzyme activity. - Plant Nutrition and Fertilizer Science, 16(6), 1472-1478. (In Chinese with English abstract).

Liu, S.Q., Pu, Y.L., Zhang, S.R., Wang, C., Deng, L. 2004. Spatial change and affecting factors of soil cation exchange capacity in Tibet. - Journal of Soil Water Conservation, 18(5), 1-5. (In Chinese with English abstract).

Liu, Z.W., Duan, E.J, Liu, Z.M., Feng, S.Y. 2009. Soil polarization of pure forests in the semi-humid loess hilly area of North Shaanxi, China. - Acta Ecologica Sinica, 29(10), 5696-5707.

Liu, Z.W., Duan, E.J., Fu, G., Cui, F.F, Gao, W.J. 2007. A new concept: soil polaziration in planted pure forest. - Acta Pedologica Sinica, 44(6), 1119-1126. (In Chinese).

Lu, R.K. 1999. Methods for soil agricultural chemical analysis. Beijing, China Agricultural Science and Technology Press. (In Chinese).

Nanjing Institute of Soil Science, Chinese Academy of Sciences. 1985. Analysis of soil microoganism. Beijing, Science Press. (In Chinese).

Osono, T., Takeda, H. 2004. Potassium, calcium, and magnesium dynamics during litter decomposition in a cool temperate forest. - Journal of Forest Research, 9(1), 23-31.

Pan, F., Lu, J., Liu, W., Geng, M., Li, X., Cao, W. 2011. Effect of different green manure application on soil fertility. - Plant Nutrition and Fertilizer Science, 17(6), 1359-1364. (In Chinese with English abstract).

Qi, Z.M, Wang, K.Y., Song, G.Y., Yang, W.Q. 2004. Bio-chemical properties of the forest floor in subalpine bamboo communities in western Sichuan. - Acta Ecologica Sinica, 24(6), 1230-1236.

Sun, Y., Zhao, X.H., He, W.X., Gao, Y.J., Cao, W.D. 2011. Effect of green manure on soil enzyme activity. - Acta Agriculturae Boreali-occidentalis Sinica, 20(3), 115-119. (In Chinese).

Wang, D., Wang, B., Dai, W., Li, P. 2011a. Sensitivity analysis of variables correlated to soil organic matter in Chinese fir plantations. - Journal of Beijing Forestry University, 33(1), 78-83. (In Chinese).

Wang, F., Zhang, J.S., Gao, P.C. 2011b. Effects of application of different organic materials on soil 
microbiological properties and soil fertility in Weibei rainfed highland. - Plant Nutrition and Fertilizer Science, 17(3), 702-709. (In Chinese with English abstract).

Wang, J., Jin, Z.X. 2006. Effect of drought-enduring herbage-little crest grass on the fertility improvement of grey brown desert soil in Heihe Valley. Chinese Journal of Soil Science, 37(3), 487-489. (In Chinese).

Wang, X.L., Yan, X.D., Xu, Y.P. 2012. The decomposition rule of covered soybean green manure and its effect on soil nutrient content. - Chinese Soil and Fertilizer, 5, 57-60.

Zhang, D.,Yao, P., Li, J., Zhao, N., Wang, Z., Yu, C., Cao, Q., Cao, W., Gao, Y. 2013. Effects of two years' incorporation of leguminous green manure on soil properties of a wheat field in dryland conditions. - Acta Ecologica Sinica, 33(7), 2272-2281.
Zhang, L.P., Zhang, X.C., Liu, Z.W., Sun, Q., Wang, S.B., Sun, H.Y., Yu, W.F., Liu, Y.J. 2008. Effect of plantation litter decomposition on soil properties. - Journal of Northwest A\&F University, 36(9), 87-92.

Zhang, Q., Cai, C.F. 2004. Forest soil degradation research and preventive strategy: a review. - Ecology and Environment, 13(04), 677-680.

Zhang, X.H., Xu, B.C., Li, F.M. 2008. Nutrient equilibrium and distribution along soil profile of three legumes on highland Loess Plateau Chinese. Journal of Eco-Agriculture, 16(4), 810-817. (In Chinese).

Zhao, N., Zhao, H.B., Yu, C.W., Cao, Q.H., Li, M., Cao, W.D., Gao, Y.J. 2011. Nutrient releases of leguminous green manures in rainfed lands. - Plant Nutrition and Fertilizer Science, 17(5), 1179-1187. (In Chinese with English abstract). 